\title{
ATIVIDADES DE PRODUÇÃO DE TEXTOS EM LIVROS \\ DIDÁTICOS DO ENSINO MÉDIO: \\ UMA PRÁTICA \\ DISCURSIVA
}

\author{
LAS ACTIVIDADES DE PRODUCCIÓN DE TEXTO EN LOS LIBROS DE TEXTO DE LA \\ ESCUELA SECUNDARIA: UNA PRÁCTICA DISCURSIVA
}

TEXT PRODUCTION ACTIVITIES IN HIGH SCHOOL TEXTBOOKS: A DISCURSIVE PRACTICE

Adelino Pereira dos Santos*

Universidade do Estado da Bahia

RESUMO: A partir de um dispositivo teórico heterogêneo, o trabalho de pesquisa apresentado neste artigo procede de nossa tese de doutorado, que teve como objetivo de investigação analisar edições de livros didáticos de Matemática, Química, Física, Biologia, História, Geografia e Língua Portuguesa, distribuídos pelo Programa Nacional do Livro para o Ensino Médio (PNLEM) no ano de 2009 e adotados por três escolas na região do Recôncavo do estado da Bahia, para: 1 - descrever que condições de escrita são fornecidas aos alunos do Ensino Médio; 2 - analisar se as atividades de produção de textos escritos contribuem para a formação de produtores de textos autênticos; 3 - apresentar uma relação dos gêneros discursivos sugeridos para a produção de textos escritos; e, 4 - identificar que concepções e/ou pressupostos teóricos sobre língua e sobre texto podem ser inferidos a partir da análise discursiva das atividades de produção de textos escritos. Neste artigo, apresentamos uma síntese das análises de apenas duas das coleções didáticas, uma de Português e outra de Matemática. A análise discursiva revelou a predominância do Discurso Pedagógico Tradicional sobre o Conteúdo de Língua Portuguesa (DPT) na origem e constituição da maioria das atividades de produção de textos escritos nos livros didáticos investigados.

PALAVRAS-CHAVE: Livros didáticos do Ensino Médio. Atividades de produção de textos. Prática discursiva.

RESUMEN: Desde un dispositivo teórico heterogéneo, el trabajo de investigación presentado en este artículo proviene de nuestra tesis doctoral, dirigida a analizar las ediciones de libros de texto de Matemáticas, Química, Física, Biología, Historia, Geografía y Portugués, repartidos por el Programa Nacional del libro para la Educación Secundaria (PNLEM) en 2009 y adoptados por tres escuelas en la región Reconcavo, en el Estado de Bahía, Brasil, a: 1 - describir que las condiciones escritas se proporcionan a los estudiantes de la escuela secundaria; 2 - analizar si las actividades de producción de textos escritos contribuyen a la formación de los productores de textos auténticos; 3 - proporcionar una lista de los géneros propuestos para la producción de textos escritos; y 4 identificar qué conceptos y / o supuestos teóricos sobre el lenguaje y sobre el texto se pueden inferir a partir del análisis discursivo de las actividades de producción de textos escritos. En este artículo, se presenta un resumen del análisis de sólo dos de las colecciones de enseñanza, uno portugués y uno de matemáticas. El análisis del discurso revela el predominio del discurso educativo tradicional 
sobre el contenido del portugués (DPT) en su origen y constitución de la mayoría de las actividades de producción de textos escritos en los libros de texto investigados.

PALABRAS CLAVE: Los libros de texto de la escuela secundaria. Las actividades de producción de texto. La práctica discursiva.

ABSTRACT: From a heterogeneous theoretical device, the research work presented in this article comes from our doctoral thesis, aimed to analyze textbook editions of Mathematics, Chemistry, Physics, Biology, History, Geography and Portuguese, distributed by the National Book Program for Secondary Education (PNLEM) in 2009 and adopted by three schools in the region of Reconcavo in the state of Bahia, Brazil, to: 1 - describe the written conditions that are provided to high school students; 2 - analyze whether the production activities of written texts contribute to the formation of producers of authentic texts; 3 - provide a list of suggested genres for the production of written texts; and 4 - to identify which concepts and / or theoretical assumptions about language and about text can be inferred from the discursive analysis of written texts production activities. In this article, we present a summary of the analysis of only two of the teaching collections, one of Portuguese and one of Mathematics. The discursive analysis revealed the predominance of the Traditional Educational Discourse on the Portuguese language content (DPT) in the origin and constitution of most production activities of written texts in the textbooks investigated.

KEYWORDS: High school textbooks. Text composition activities. Discursive practice.

\section{INTRODUÇÃO}

Em setembro de 2015 o Ministério da Educação (MEC) colocou em consulta pública a Base Nacional Comum Curricular para a Educação Básica, o que tem possibilitado, desde então, inúmeras discussões, questionamentos e críticas, mais uma vez, sobre a natureza dos conteúdos a serem ministrados no âmbito das disciplinas da Educação Básica. Um ano depois, em setembro de 2016, o Governo Federal publicou uma Medida Provisória (MP) em que impõe uma imediata reforma do Ensino Médio. Esses atos e documentos governamentais propiciam a necessidade de reflexões não só sobre práticas pedagógicas e redimensionamentos curriculares, mas igualmente sobre os aspectos ideológicos que possibilitam e condicionam a manutenção dos (mesmos) conteúdos das disciplinas e programas de ensino, bem como o aparecimento de (novos) saberes, em acordo com o atual estágio de desenvolvimento das sociedades contemporâneas.

Neste sentido, pesquisas como a que realizamos e que apresentamos neste artigo se justificam não só pelo caráter de denúncia, importante bandeira política na luta pela mudança, como tão bem reivindica Irandé Antunes (2003), mas, sobretudo, por possibilitar reflexões que nos encaminhem para a busca de soluções para os problemas apontados. Neste trabalho, ao discutirmos sobre a situação das atividades de produção de textos (APT) em livros didáticos do Ensino Médio, divisamos as APT como uma "arena de luta" (BAKHTIN, 2004) em que sobrevivem pré-construídos sobre o fazer pedagógico, reveladores de concepções de língua e de texto historicamente arraigadas nas práticas escolares, de modo que tornam a escola e suas práticas discursivas, entre elas as APT, infensas às descobertas científicas e às reflexões filosóficas oriundas dos campos teóricos da Sociolinguística, da Linguística do Texto, das Análises de Discurso, das Teorias da Enunciação, da Filosofia da Linguagem, da Linguística Aplicada, entre outras tantas contribuições que, se consideradas, certamente provocariam parte da transformação nos rumos do ensino de língua materna, o que há tanto almejamos.

O trabalho de pesquisa aqui relatado foi direcionado pelos seguintes questionamentos: Que condições de escrita são oferecidas aos alunos do Ensino Médio através das atividades de produção de textos presentes em livros didáticos fornecidos pelo Programa Nacional do Livro para o Ensino Médio (PNLEM)? Até que ponto as atividades de produção de textos escritos presentes em edições recentes de livros didáticos do Ensino Médio contribuem para a formação de produtores de textos autênticos?' ${ }^{1}$ Que gêneros discursivos são sugeridos como atividades de produção de textos em livros didáticos do Ensino Médio? Que concepções e/ou pressupostos teóricos sobre língua e sobre texto podem ser inferidos a partir da análise das atividades de produção de textos presentes em edições recentes dos manuais didáticos do Ensino Médio?

${ }^{1}$ Compreendemos por textos autênticos aqueles que são produzidos por uma real necessidade interlocutiva, isto é, cujas condições de produção pressupõem pelo menos dois interlocutores, uma necessidade de comunicação (um objetivo comunicacional ou interlocutivo a ser alcançado) e os meios adequados para a realização do processo interativo. 
Em nossa tese de doutorado, defendida em maio de 2010, fizemos a análise de dez coleções de livros didáticos, dos componentes curriculares Química, Física, Matemática, Biologia, Português, História e Geografia, constituintes do PNLEM 2009, em uso naquele ano (2010) por três escolas públicas de grande porte do município de nossa residência, na região do Recôncavo da Bahia. Neste artigo, apresentamos, em contraponto, dados relativos a apenas duas das coleções investigadas, uma da disciplina de Língua Portuguesa e outra de Matemática, por serem representativas, em extremos, dos demais resultados encontrados.

A análise das APT nos permitiu chegar à conclusão de que nove das dez coleções de livros didáticos investigadas não traziam contribuições significativas para o desenvolvimento da proficiência de produção de textos escritos pelos alunos do Ensino Médio; e de que na origem e constituição de tais atividades, compreendidas como práticas discursivas, predomina a presença do Discurso Pedagógico Tradicional sobre o Conteúdo de Língua Portuguesa (DPT), justificado pelas formações discursivas a que se filiaram os autores dos livros didáticos no momento de elaboração das APT, em um jogo de formações imaginárias que revela as imagens dos autores dos livros didáticos sobre si mesmos, sobre os alunos do Ensino Médio, sobre língua e sobre texto, matérias substanciais das atividades de produção de textos.

Salientamos que foi nossa intenção, no trabalho de pesquisa, criar um dispositivo teórico-metodológico a partir de contribuições epistemológicas diversas, que nos permitisse chegar às respostas para as perguntas propostas. Temos consciência dos limites deste trabalho e de que na expressão de nosso dizer fizemos silêncios sobre tantas outras coisas, não ditas. Alguns silenciamentos (ORLANDI, 1997) foram propositais, outros foram incômodos não resolvidos, impossibilidades; outros tantos promessas e esperanças de estudos em futuro próximo. São hoje muitas as pesquisas que abordam os livros didáticos do Ensino Fundamental, constituintes do Programa Nacional do Livro Didático. São poucos, contudo, os trabalhos específicos sobre o PNLEM, de modo que esperamos que este trabalho possa contribuir, de alguma forma, para sua melhoria.

\section{AS APT COMO UMA PRÁTICA DISCURSIVA}

Se levarmos em consideração a assertiva de Bakhtin (2003) de que o conteúdo temático, o estilo e a construção composicional dos gêneros discursivos, além de estarem indissoluvelmente ligados ao todo do enunciado, serem também determinados pela especificidade de um determinado campo da comunicação, podemos facilmente compreender porque na escola ainda não se produzem textos como seria de se esperar de um aluno do EM, após ter concluído os nove anos de Ensino Fundamental: faltam-lhe as condições propícias ao desenvolvimento das habilidades de produção de textos. Divisamos a escola como um local de conflitos porque nela "deságuam todos os rios" que arrastam consigo os interesses, confrontos, (des)motivações, consensos e dissensos que permeiam a sociedade como um todo. Não se pode admitir neutralidade, nem mesmo nas mínimas ações que se praticam na escola. Toda ação é sempre motivada. As motivações se originam nos jogos de interesses, ainda que bem intencionados, característicos da sociedade de consumo, do estado atual do sistema capitalista de produção e circulação de bens e serviços que todos nós, neste recanto do Ocidente, estamos inseridos. Por isso mesmo, compreendemos que toda prática escolar, sejam aquelas que envolvem professores e alunos no trabalho pedagógico de ensinar/fazer aprender, sejam as ações que se referem à gestão administrativa, sejam as oriundas dos profissionais de apoio e técnico-administrativos, todas essas ações são, necessariamente, práticas mediadas por discursos vários que, juntos, constituem o domínio discursivo escolar (particularizando-se em cada instituição específica). É a isso que chamamos aqui de prática discursiva.

Furlanetto (2007, p. 145) assevera que as práticas discursivas estão necessariamente associadas às comunidades que as realizam: "Em se tratando da instituição escola, podemos observar algumas práticas bem específicas: 'dar' aulas, preparar aulas, participar de conselhos de classe; fazer os 'deveres', bater papo no recreio, 'produzir textos' ou 'redação', ler (com vários objetivos)”. Essa autora chama ainda atenção para o fato de que, no contexto escolar brasileiro, está ainda em evidência um claro conflito "[...] entre o conhecimento que é produzido na academia e sua eventual aplicação” (FURLANETTO, 2007, p. 146) em termos de práticas escolares. 
No que se refere à produção de textos, veem-se ainda discursos em oposição, embate, ambiguidade e entrelaçamento, conforme discutimos alhures (SANTOS, 2007), evidenciados tanto pela fragilidade teórico-conceitual que sustenta as orientações para a produção de textos, quanto pela predominância de um único gênero, a redação de vestibular, do ENEM ou de concurso público, que restringe praticamente toda atividade de escrita no Ensino Médio (EM).

Convivem em conflito, às vezes velado, dissimulado, às vezes em claro confronto, concepções divergentes de como "fazer uma redação" e "produzir um texto". A primeira expressão se referiria à prática escolar do aluno do EM escrever um texto como uma espécie de treinamento, com objetivos comunicativos praticamente inexistentes, escrever apenas como uma obediência a um comando do professor ou do livro didático, para alcance de metas tipicamente escolares. Já a expressão "produção textual” se reservaria, conforme a assertiva de Geraldi (1997), para quando os alunos escrevessem um texto não para a escola, mas na escola enquanto espaço de interlocução, em que os alunos, recategorizados para a condição de autores, se colocariam como sujeitos de seu dizer, como interlocutores, como disse Geraldi (1997), mesmo que esse gesto seja uma atitude responsiva a uma provocação da escola/professor, participando assim do grande diálogo social, conforme teorizado por Bakhtin (2004).

Sobre a prática (discursiva) de produção de textos no EM, Antunes (2005) elenca duas insuficiências principais, que passamos a comentar:

I - há uma primazia quase que absoluta da oralidade sobre a escrita; uma oralidade que se manifesta em gêneros primários, da conversação cotidiana às simples explicações e às vezes "traduções" do escrito. Reservam a escrita apenas para os apontamentos de aula e a restringem às atividades das aulas de redação. Chamemos aqui a atenção para o fato de que seria até produtivo e aumentaria significativamente a competência comunicativa do aluno do EM se esse predomínio da oralidade incluísse abundantemente os gêneros formais, das instâncias públicas, conforme sugere Geraldi (1996), visto que esses gêneros, indissoluvelmente (BAKHTIN, 2003) se relacionam com a escrita - às vezes são gêneros escritos de manifestação oral;

II - as oportunidades de escrita, quando aparecem, restringem-se aos objetivos imediatos das disciplinas, de fins apenas escolares, sem as perspectivas inspiradoras do uso da língua por meio de variados gêneros discursivos, para alcance dos múltiplos propósitos comunicativos e interativos que caracterizam a complexidade da vida nas sociedades humanas hodiernas.

A consequência dessas duas insuficiências, ainda segundo Antunes (2005), é uma "escrita falseada", uma escrita para nada e para ninguém, sem um leitor à vista, quando nem mesmo o professor assume essa função: "[...] nem mesmo o professor que vai ler o texto dos alunos costuma assumir esse papel de leitor, atropelado que é pelo outro papel de corretor" (ANTUNES, 2005, p. 27).

Temos que pontuar aqui que nem sempre a culpa por esse processo é (apenas) do professor, mas também de todas as limitações que lhe são impostas. Limitações que vão desde resquícios de sua formação escolar e acadêmica à quantidade de alunos em sala de aula, à própria dinâmica do tempo escolar, quando reservam para as atividades de produção de textos (redação) apenas uma ou duas aulas por semana. O que fazer em cinquenta ou cem minutos quando a classe chega a atingir noventa e dois alunos, como pudemos averiguar em uma das escolas que usavam os livros didáticos objetos de nossa pesquisa?

Antunes (2003) assevera que, ao lado dessas dificuldades, duas mais se ressaltam: a primeira diz respeito à própria situação de vida do professor, que impossibilita a ele ser leitor, no sentido mais amplo desse termo, ser um "escrevente" assíduo e um pesquisador capaz de lançar olhos diferenciados sobre sua própria prática. A segunda dificuldade se manifesta pela própria (in)compreensão de o que é o processo de escrever, o que se traduz em práticas pedagógicas que mais afastam os alunos da escrita, desvirtuando, consequentemente, os propósitos educacionais da escola.

Muitas dessas dificuldades poderiam desaparecer do cotidiano escolar se a escola como um todo (e não apenas o professor de Língua Portuguesa) pudesse compreender que a escrita é uma atividade regida por princípios que devem ser respeitados em uma atividade de produção de textos. Antunes (2005) pontua pelo menos dez desses princípios, que elencamos aqui por paráfrase ao texto da autora, quando nos ensina que a escrita é também uma atividade de interação social. Isso significa que o ato da escrita não é, como se tem dito, um ato solitário. Escreve-se para o outro, cuja presença permanece desde o passo inicial, que determina mesmo a escolha dos objetivos e do gênero a ser escrito, até o momento final, em que o leitor, interlocutor no processo interativo, infere a

Santos | atividades de produção de textos em livros didáticos do ensino médio: uma prática discursiva 
intencionalidade de quem escreveu e, por sua vez, contribui com o processo de escrita dando o seu crédito de coerência, promoção da aceitabilidade do escrito. Em termos de prática pedagógica, isso significa que a escrita escolar, a produção de textos no EM deve oferecer ao aluno a oportunidade de escrever para um sujeito real, em uma situação autêntica de escrita, de modo que, como nos diz Antunes (2005, p. 28) o aluno possa contar com esse destinatário real, "do outro lado da linha”, sujeito autêntico que será a medida de avaliação de seu texto.

Na perspectiva da interação, escrever só pode ser uma atividade cooperativa. Muitas das dificuldades do aluno do EM no que se refere ao ato de escrever se dão porque ele não pode contar com um leitor autêntico, uma situação real de comunicação de modo que ele possa, com segurança, fazer as escolhas necessárias para alcance de seus propósitos interativos. Até mesmo as seleções lexicais podem ser feitas tendo o outro como medida. O estilo, o tom são igualmente selecionados como elementos imprescindíveis à construção da coerência textual que, por sua vez, é um fenômeno que depende, inteiramente, da cooperação, construção recíproca de quem escreve e de quem lê o texto. O produtor textual leva isso em consideração no processo de escrita, na medida em que faz a dosagem das pressuposições, dos jogos de inferência, do que deve ficar implícito ou deve ser explicitado no texto, de modo a ser percebido ou inferido pelo leitor.

Escrever deve ser, sempre, uma atividade contextualizada. Mesmo os gêneros mais formais das instâncias públicas de comunicação, do domínio discursivo da administração empresarial ou da burocracia pública, por exemplo, mesmo esses gêneros de estruturas mais rígidas, quase sempre formulaicos, tais como o ofício, o memorando, a ata, o requerimento, sofrem, no processo de escrita, a contingência do contexto de ocorrência. $\mathrm{O}$ aluno do EM deveria aprender que a comunicação escrita efetiva, autêntica, faz-se com sucesso na medida em que são levados em conta os fatores da situação imediata, restrita, bem como do contexto social mais amplo. Nesse sentido, vale aqui a ressalva de que a escola do EM ganharia muito se adotasse, para as atividades de produção de textos, a contextualização por meio de projetos pedagógicos, na medida em que esses pudessem fornecer os fatores de contextualização, de modo a tornar a escrita funcional e a por a língua em uso por uma real necessidade interlocutiva.

$\mathrm{O}$ ato de escrever deve ser compreendido como uma atividade necessariamente textual. Isso pode parecer pleonástico, mas o aluno do EM ainda se depara com atividades de "escrita" que desrespeitam a textualidade. Escrever introduções ou conclusões de textos que ele, o aluno, não planejou, não sabe os objetivos, não sabe para quem se destina, ou quando é obrigado a escrever dentro dos limites de certo número de linhas, "escrever por escrever" para apenas cumprir uma tarefa, para levar adiante o programa de ensino, para preencher o tempo da aula, tudo isso são exemplos de antiescrita, e o resultado é, quase sempre, um "amontoado" de palavras sem sentido, um não-texto, enfim. Outras vezes o "texto" deve ser escrito em função de um exemplo de aplicação de um tópico gramatical, uso de orações coordenadas e subordinadas, para exemplificação do uso de conjunções: portanto, consequentemente, porém, no entanto. Tudo isso a pretexto, às vezes, de ensinar a argumentar, ou a "escrever bem", de resultados inevitavelmente contraproducentes.

Escrever com autenticidade, conforme defendemos neste trabalho, só pode ser por uma atividade tematicamente orientada. A escrita de qualquer gênero discursivo depende inteiramente de um tema condutor que funciona como a linha em uma agulha, que vai tecendo, em fios, a textualidade. O tema se relaciona com o ponto de vista do produtor do texto. Não importa o tipo textual predominante no gênero, se descritivo, se dissertativo, se narrativo, ou se todos esses tipos em interação em um mesmo texto, como bem exemplificou Marcuschi (2008). Toda passagem do texto fica "amarrada” em função do tema. Em termos de prática pedagógica na sala de aula do EM, isso significa que a produção de textos não pode ser uma "atividade livre", à mercê da criatividade do aluno, ou a obediência cega à "ordem pronta" do "escreva um texto" sem fornecer ao aluno a orientação temática que sustente o seu trabalho de escrita.

Escrever é uma atividade intencionalmente definida. Um dos requisitos essenciais no processo de escrita que deve ser levado em conta nas atividades de produção de textos no EM, dentro da etapa do planejamento do texto, é o estabelecimento dos objetivos. Ninguém escreve bem se não sabe que meta, que fim quer atingir, assim como não se chega a lugar algum se não se sabe, previamente, aonde se quer chegar. O estabelecimento dos objetivos ajuda a definir o roteiro do texto. Todo dizer deve ser um dizer situado, para alcance de um propósito, com vistas a uma mudança de situação, visto que escrever, assim como falar, é um agir que se faz com palavras, um comportamento intencionalmente definido. 
Escrever é uma atividade que envolve, além dos elementos linguisticos, os fatores pragmáticos. Aqui, conforme mencionamos anteriormente, o aluno do EM deve ter a consciência de que "não se escreve apenas com palavras", mas na mesma proporcionalidade, levando em consideração os fatores pragmáticos do processo interativo, o quando, o onde, o para quem, o que dia é hoje, em que momento da História, sob que circunstância sociopolítica e cultural. Enfim, a situação restrita e imediata, bem como a contextualização histórica que define a vida em sociedade.

Escrever é uma atividade que se manifesta em gêneros discursivos. Definir o gênero de discurso a ser produzido deve ser a obrigação primeira de qualquer atividade de produção de textos. No contexto do EM nem sempre isso acontece, visto que o termo redação acaba ganhando o estatuto de um texto "genérico", o chamado de redação de vestibular, do ENEM ou de concurso público. Algumas vezes, sem a frequência necessária à boa prática de escrita, propõe-se a produção de narrativas (um conto, uma crônica, um relato de experiência). Muitas vezes ainda a escrita é imposta como um mero exercício escolar de "descrever" uma paisagem, uma personagem etc., sem que essa descrição esteja tematicamente situada ou ocorra no interior de um gênero previamente definido.

Escrever é uma atividade que retoma outros textos. Aqui vale o princípio assaz óbvio de que ninguém escreve do nada. É o princípio do dialogismo bakhtiniano, das vozes sociais que falam, que se manifestam nas vozes dos sujeitos que escrevem. É o princípio também das relações que se estabelecem entre os textos, seja pela retomada do tema (intertextualidade temática), seja por meio da estrutura ou do gênero (intertextualidade da forma), seja pela apresentação de um gênero com forma e/ou função de outro (intergenericidade), seja pela manifestação dos discursos que os textos veiculam (a interdiscursividade), materializados nas estratégias do dizer, tais como as paráfrases, as paródias, as alusões, ou mesmo por formas composicionais, tais como o resumo, o comentário etc.

Por fim, escrever é uma atividade em relação de interdependência com a leitura. No contexto do EM, toda atividade de produção de textos deveria ser precedida por atividades de leitura, de modo a fornecer aos alunos o contato com o tema, possibilitar o acionamento dos conhecimentos prévios, possibilitar a escolha do ponto de vista, assim como viabilizar o conhecimento particularizado do gênero discursivo a ser escrito, além de contribuir para o enriquecimento do nível de informatividade (relação dado/novo) do texto a ser produzido.

Esses princípios que regem o ato de escrever devem ser operacionalizados em etapas, que correspondem às etapas de produção de um texto, que, ainda segundo Antunes (2003), devem ser as seguintes, em resumo:

1 - A etapa do planejamento, que corresponde aos processos de a) delimitar o tema do texto e aquilo que lhe dará unidade; b) eleger os objetivos; c) escolher o gênero; d) delimitar os critérios de ordenação das ideias; e, por fim, e) prever as condições dos leitores e a forma linguística (mais formal ou menos formal) que o texto deve assumir;

2 - A etapa da escrita, que "[...] corresponde à tarefa de pôr no papel, de registrar o que foi planejado. É a etapa da escrita propriamente dita, do registro, quando concretamente quem escreve vai seguir a planta esboçada e dar forma ao objeto projetado", ao texto (ANTUNES, 2003, p. 55);

3 - A etapa da revisão e da reescrita, que corresponde ao processo de análise do que foi escrito para tomar as decisões "do que fica e do que saí do texto", de observar os fatores de coesão, de revisar os fatores estruturais e formais (da superfície do texto), tais como a organização dos parágrafos e períodos, a obediência ao sistema ortográfico; de confirmar se os objetivos foram alcançados, identificar se há divergências e contradições no desenvolvimento do tema, se há, enfim, clareza no desenvolvimento das ideias, importante para o estabelecimento da coerência do texto.

Aceitas as APT como uma prática discursiva, propomos, neste trabalho, que os livros didáticos para o ensino médio (LDEM) sejam entrevistos como um gênero do discurso, um gênero secundário (complexo), conforme a perspectiva de Bakhtin (2003), o que passamos a discutir na próxima seção. 


\section{OS LDEM: SUPORTES DE GÊNEROS OU GÊNEROS DE DISCURSO?}

A decisão de classificarmos os LDEM como gêneros do discurso ou suportes de gêneros demanda a análise prévia da relação entre os suportes e os textos/discursos que eles transportam.

Marcuschi (2008, p. 173) nos informa que "Ainda inexistem estudos sistemáticos a respeito do suporte dos gêneros textuais. Apenas agora iniciam as investigações sistemáticas e muitas são as indagações”. Por isso mesmo, pouco podemos acrescentar a esses questionamentos, já que foi outro o propósito de nossa investigação. Contudo, por certo que consideramos a relevância da temática, pois percebemos que a mudança de suporte altera substancialmente os sentidos que podem ser atribuídos a um texto ou a percepção da manifestação de um discurso. Um simples enunciado ganha ou perde valor de verdade a depender do suporte que o sustenta ou veicula. "Amanhã não haverá aula” poderá adquirir o sentido de uma informação importante para alunos e professores de uma escola primária ou ainda o sentido de uma "brincadeirinha de criança", se o texto estiver escrito no quadro da sala de aula, com claros indícios de que foi escrito por um dos alunos da turma, ou se vier como um "bilhetinho aos pais", reproduzido e assinado pela professora ou pela direção da escola. Logicamente que se pode questionar que foram, decididamente, os outros elementos do contexto que determinaram o sentido circunstancial que pôde ser atribuído ao texto. Não negamos isso. Entretanto, pensamos ser relevante incluir os suportes dos textos/gêneros de discurso entre os fatores de contextualização, o que é o mesmo que afirmarmos que o suporte de um gênero de discurso é tão significativo para os sentidos do texto ou as manifestações de discursos quanto as informações paratextuais de saber a quem pode ser atribuída a autoria do texto do exemplo acima ou mesmo o local e a data da inscrição.

Em termos de discurso, podem-se fazer análises diferenciadas, com prováveis resultados igualmente distintos, se a inscrição "I love New York", mundialmente veiculada com o desenho de um coração vermelho em meio a letras pretas substituindo e significando a palavra love, aparece em uma camiseta branca, comprada em uma lojinha de um shopping center de Salvador, de São Paulo ou mesmo da cidade de Nova Iorque, ou se vem escrita na parte superior da homepage de uma agência de viagens ou como tatuagem na pele branca de um norte americano qualquer. Nas duas primeiras situações, um sentido comercial de valorização da cidade se manifesta de modos diferenciados no site e na camiseta; no caso da tatuagem, pode-se perceber um discurso de nostalgia ou de patriotismo veiculando o sentido de "amor à minha terra", declaração afetiva pelo local de nascimento ou de adoção.

A discussão sobre os suportes se torna ainda mais complexa se pensarmos na dificuldade que temos em definirmos a natureza dos veículos de comunicação: por certo que não são os mesmos os procedimentos de escrita de um anúncio publicitário a ser veiculado por uma rádio local, por um canal de televisão, por um site da internet ou nas folhas de uma revista semanal ou mensal de informação. Também, as informações sobre a qualidade/valor nutricional de um alimento ganham contornos diferenciados se veiculadas em um gênero de uma embalagem do produto ou se contidas em um livro de dietas.

Marcuschi (2008, p. 174-5) define suporte nos seguintes termos: “[...] entendemos aqui como suporte de um gênero um locus físico ou virtual com formato específico que serve de base ou ambiente de fixação do gênero materializado como texto”. O autor ainda apresenta a distinção entre os suportes convencionais e os incidentais. Os primeiros seriam aqueles "[...] que foram elaborados tendo em vista a sua função de portarem ou fixarem textos"; enquanto que os segundos "[...] operam como suportes ocasionais ou eventuais", sendo que "[...] em princípio toda superfície física pode, em alguma circunstância, funcionar como suporte" (MARCUSCHI, 2008, p. 177).

Entre os vários exemplos de suportes convencionais apresentados por Marcuschi (2008), tais como o jornal diário, a revista semanal ou mensal, o rádio, a televisão, o telefone, o quadro de avisos etc., encontramos o livro e o livro didático. Para Marcuschi (2008, p. 179), em termos de discussão sobre suportes, não há distinção relevante entre livro e livro didático, "[...] já que se trata de fenômenos similares”. Contudo, o autor argumenta que há elementos específicos do livro didático, no que diz respeito, sobretudo, à sua funcionalidade, que torna relevante a distinção entre esses suportes. Marcuschi (2008) chama a atenção para o aspecto da funcionalidade e não da função, já que, para ele, uma carta, um poema, uma história em quadrinhos etc. continuariam sendo o que são sem mudarem suas características pelo fato de terem migrado para o interior de um livro didático. Esses gêneros, no entanto, no 
interior de um romance perderiam as suas características, conforme também argumenta Bakhtin (2003) na definição dos gêneros secundários (complexos).

Para Marcuschi (2008, p. 179), "O livro didático é nitidamente um suporte textual”, em especial o livro didático de Língua Portuguesa, que comportaria um vasto conjunto de gêneros, com relevo para os gêneros da esfera do discurso pedagógico, para além daqueles de circulação externa à escola e inseridos no interior do livro didático, tais como a explicação textual, os exercícios escolares, a redação, a instrução para a produção textual, entre outros.

Como se vê, Marcuschi (2008) considera os LDEM como suportes que abrigam conjuntos de gêneros e as APT como um gênero textual específico. Em posição divergente à de Marcuschi (2008), Clecio Bunzen e Roxane Rojo (2005) consideram os LDEM, a partir de estudos voltados para a análise de livros didáticos de Língua Portuguesa, como um enunciado num gênero discursivo, no sentido de gênero do discurso conforme veiculado nos textos do Círculo de Bakhtin (BAKHTIN, 2003, 2004). Para esses autores, os LDEM são fenômenos historicamente datados que visam a atender a interesses de uma esfera de produção e de circulação, de onde retiram seus temas, formas de composição e estilo:

Neste trabalho, entretanto, estamos defendendo que há sim unidade discursiva, autoria e estilo no LD, proporcionada via fluxos e alinhamentos do discurso autoral, responsável pela articulação de textos em gêneros diversos e que tal processo indicia muito mais a produção de enunciados em um gênero do discurso do que um conjunto de textos num suporte, sem um alinhamento específico, sem estilo e sem autoria. (BUNZEN; ROJO, 2005, p. 86).

Os argumentos de Bunzen e Rojo (2005) são de que os autores dos LDEM e todos os agentes envolvidos no processo de sua elaboração produzem enunciados num gênero do discurso, visto que, conforme cita Bakhtin $(2003,2004)$, qualquer forma de interação verbal, falada ou escrita, atualiza formas consagradas de expressão e é movida pela vontade de dizer de um locutor, manifestada através de um gênero discursivo. Nesse sentido, para esses autores, os LDEM possuem temas, que são os objetos de ensino, uma expectativa interlocutiva específica, representada pelos alunos e professores das instituições públicas e particulares que adotam os LDEM, os editores dos manuais e os avaliadores que classificam, aprovam ou reprovam os LDEM para fazerem parte ou não do PNLEM. Os LDEM possuiriam ainda um estilo próprio, facilmente perceptível, em nossa pesquisa, pela descrição que fazemos das condições de aparecimento das APT no interior de cada coleção analisada, conforme demonstramos na próxima seção. Por isso mesmo, neste trabalho, comungamos com Bunzen e Rojo (2005) e aceitamos a concepção de que os LDEM são gêneros de discurso (secundários, complexos, conforme nos orienta Bakhtin (2003)), o que nos leva a conceber, igualmente, as APT como práticas discursivas que se constituem no interior do gênero LDEM.

\section{ANÁLISE DO LIVRO DIDÁTICO DE PORTUGUÊS - COLEÇÃO 10: A NEGAÇÃO DA ESCRITA}

A Coleção 10, Português, apesar de ser constituída por um volume único, não apresenta diferenças significativas em relação à Coleção 09, de três volumes. Este manual didático também está dividido em três partes independentes: "Literatura”, "Gramática” e "Redação e Leitura", sendo que somente nesta última parte foram encontradas as atividades de produção de textos. A observação dos títulos dos capítulos (1 a 24) que integram a terceira parte deste livro didático dá-nos algumas pistas das concepções de língua e de texto (e, consequentemente, do trabalho de ler e de escrever) que subjazem às atividades de produção de textos presentes neste manual - Terceira Parte: Redação e Leitura: Liberação da linguagem e do pensamento; Exercícios de imaginação; Leitura: interpretação e análise de texto; Experiências de enumeração ( $1^{\mathrm{a}}$ parte); Experiências de enumeração (2a parte); A descrição; A narração; A dissertação; Descrição: sensibilidade e imaginação; Experiências de aprofundamento da descrição; O mundo narrado; Começando a história; A apresentação da personagem; A construção do enredo; Enredo linear e não-linear; Narrador: a voz que conta a história; O mundo dissertativo; A delimitação do tema; Assumindo um ponto de vista; A argumentação causal: o(s) porquê(s); A importância do exemplo; A estrutura do texto; Jogos lógico-expositivos; A linguagem dissertativa. 
Como se pode inferir, já pelos primeiros capítulos vê-se a língua(gem) concebida como representação do pensamento. Os textos que iniciam os capítulos, oferecidos à leitura, são textos literários, fragmentos de poemas de autores como Álvaro de Campos, Carlos Drummond de Andrade, Cecília Meireles, entre outros. Dessa forma, percebemos que escrever, produzir textos, significa, por essa perspectiva, "soltar a imaginação" para imitar os "bons escritores".

Semelhantemente à Coleção 09, as atividades de produção de textos deste livro didático não estão embasadas em nenhuma teoria de gêneros textuais/discursivos. Os autores desta coleção seguem a tipologia clássica de produção de textos com base nos tipos textuais, isto é, nas sequências linguísticas, que vai da descrição/narração à dissertação. Embora seja um material concebido também para a função precípua de ensinar a escrever, nota-se a ausência de qualquer observação sobre a diversidade de gêneros discursivos que circulam na sociedade, sobre a existência de textos que apresentam múltiplos tipos, sobre a relação entre os sentidos dos textos e as condições de produção, com o contexto histórico-social amplo e restrito. Diante disso, percebemos que as APT presentes neste manual são, assim como na coleção anterior, meros exercícios de linguagem, o que significa que a produção escrita do aluno não é verdadeiramente um ato de comunicação e interação com o outro, destinatário de seu discurso (texto), coenunciador, sujeito de sua interação. Aliás, por essa perspectiva, não se percebe “o outro do outro lado da linha”, como na bela metáfora de Antunes (2003).

Na coleção em análise, as APT que se relacionam à descrição e à narração sugerem apenas a produção de textos literários. Já as APT que enfocam o tipo dissertativo (expositivo ou argumentativo) trabalham na perspectiva da redação de vestibular e da prova do Exame Nacional do Ensino Médio (ENEM), sugerindo com isso que a única função do ensino da escrita na Educação Básica é a formação de escritores literários e a preparação para o uso futuro das habilidades de escrever nas redações de vestibulares ou do ENEM. Com isso, o manual didático nega ao aluno do EM a possibilidade de ele ser, na sua contemporaneidade, no cotidiano mesmo da escola, um autêntico usuário da língua, capaz de, através de seus textos, interagir com o mundo, construí-lo e modificálo.

Por tudo isso, vemos que essa coleção, assim como a anterior, mesmo tendo a língua como objeto de estudo/ensino, e sendo a modalidade escrita a mais valorizada porque até se confunde com escolarização, pouco contribui para o desenvolvimento da proficiência de produção de textos escritos pelo aluno do EM, visto que não possibilita a ele a participação em situações reais, autênticas de uso da língua escrita, capaz de fazê-lo agir como um sujeito ativo, dinâmico e competente, como somos todos nós, falantes do português. A análise das APT presentes nesta coleção permitiu a percepção dos seguintes resultados:

Em relação ao quesito tipologia textual, este livro didático não apresenta diversidade de gêneros discursivos nem de tipos textuais, uma vez que propõe as APT a partir de exercícios pela tipologia clássica, intrinsecamente uma tipologia escolar, já que os diversos gêneros discursivos que circulam em abundância no meio social apresentam como característica estrutural a simultaneidade de tipos, com um ou dois em predominância. Igualmente, não há diversidade de variedades nem de registros que se adéquem às condições de produção.

Quanto ao quesito condições de produção, podemos marcar como negativos todos os seus constituintes. Em algumas APT aparece o comando "mostre o seu texto para o colega", sem explicitar, contudo, as razões pelas quais o aluno do EM deveria fazê-lo ou propor revisão do texto produzido. No que diz respeito ao quesito contribuição para a construção da textualidade pelo aluno, também todos os itens nos parecem negativos. Diferentemente da Coleção 09, este livro didático de Português não propõe temas consistentes, nem relevantes, nem significativos. O item contribuição para a construção da forma composicional foi marcado negativamente porque as instruções relativas ao tipo textual em estudo não dão conta da textualidade nos níveis da coesão e da coerência quanto à continuidade temática, à progressão do tema, à articulação entre períodos e parágrafos, nem tampouco à intertextualidade, e nem faz referência à necessidade do texto não ser contraditório (à não-contradição).

Do quesito formulação das propostas, talvez poderíamos marcar positivamente somente os itens variedade na formulação e progressão das atividades. Contudo, se assim o fizermos, temos de ressaltar que a progressão implícita nas APT não necessariamente obedece ao critério de proporcionar o progresso na escrita dos alunos, aumentando, paulatinamente, o grau de complexidade, mas à simples obediência de uma ordem preestabelecida: descrição/narração no primeiro ano do EM, dissertação no segundo, revisão e treino de provas de vestibulares e do ENEM no terceiro. Não podemos, igualmente, marcar como corretas propostas de produção 
de textos que não nos parecem significativas para a aprendizagem dos alunos. Podem ser marcados negativamente também todos os itens do quesito avaliação dos textos produzidos, pois nas APT em análise não há qualquer menção ao processo avaliativo dos textos. Todas essas conclusões encontram-se sintetizadas no Quadro $01^{2}$ a segui

\begin{tabular}{|c|c|c|c|}
\hline $\begin{array}{l}\text { ATIVIDADES DE PRODUÇÃO DE TEXTOS ESCRITOS NO LIVRO DIDÁTICO } \\
\text { DE PORTUGUÊS - COLEÇÃO } 10\end{array}$ & \multicolumn{3}{|c|}{$\begin{array}{c}\text { PRESENÇA /AUSÊNCIA } \\
\text { DAS CARACTERÍSTICAS A SEGUIR E } \\
\text { IDENTIFICAÇÃO DAS APT. }\end{array}$} \\
\hline Tipologia textual & Sim & Não & APT \\
\hline Diversidade de gêneros e tipos textuais & & $\mathrm{X}$ & \\
\hline Diversidade de variedades e registros adequados à situação de produção & & $\mathrm{X}$ & \\
\hline \multicolumn{4}{|l|}{ Condições de produção } \\
\hline \multicolumn{4}{|l|}{ Explicitação da situação de produção do texto: } \\
\hline a) indicação de objetivos para a produção & & $\mathrm{X}$ & \\
\hline b) indicação de destinatários para o texto & & $\mathrm{X}$ & \\
\hline c) indicação do contexto social de circulação do texto & & $\mathrm{X}$ & \\
\hline d) indicação do veículo ou suporte & & $\mathrm{X}$ & \\
\hline e) indicação do gênero textual & & $\mathrm{X}$ & \\
\hline f) indicação da variedade e/ou registro & & $\mathrm{X}$ & \\
\hline Proposta de socialização dos textos produzidos & & $\mathrm{X}$ & \\
\hline \multicolumn{4}{|l|}{ Contribuição para a construção da textualidade pelo aluno } \\
\hline Contribuição para a elaboração temática & & $\mathrm{X}$ & \\
\hline Contribuição para construção da forma composicional do texto & & $\mathrm{X}$ & \\
\hline Contribuição para a elaboração do texto de acordo com as convenções da escrita & & $\mathrm{X}$ & \\
\hline Contribuição para as operações exigidas na produção: & & $\mathrm{X}$ & \\
\hline a) propostas de planejamento & & $\mathrm{X}$ & \\
\hline b) proposta de revisão de texto & & $\mathrm{X}$ & \\
\hline c) proposta de reelaboração de textos & & $\mathrm{X}$ & \\
\hline \multicolumn{4}{|l|}{ Formulação das propostas } \\
\hline Adequação em relação aos objetivos & & $\mathrm{X}$ & \\
\hline Variedade na formulação & $\mathrm{X}$ & & $27,28,29$ \\
\hline Clareza e correção na formulação & & $\mathrm{X}$ & \\
\hline Progressão nas atividades & $\mathrm{X}$ & & $27,28,29$ \\
\hline \multicolumn{4}{|l|}{ Avaliação dos textos produzidos } \\
\hline Presença significativa de propostas de autoavaliação & & $\mathrm{X}$ & \\
\hline Presença de proposta de avaliação coletiva, na sala de aula & & $\mathrm{X}$ & \\
\hline Presença de sugestão de leitura / avaliação por leitores externos à situação escolar & & $\mathrm{X}$ & \\
\hline
\end{tabular}

Quadro 1: Situação das APT no livro didático de Português - Coleção 10.

Fonte: produzido pelo autor. ${ }^{2}$ Quadro analítico das APT, adaptado de Costa Val (ROJO; BATISTA, 2003, p. 130). O que chamamos aqui de coleção tanto pode se referir aos três volumes de
livros didáticos correspondentes às três séries do EM ( $1^{\circ}$ ao $3^{\circ}$ ano $)$ ou a um volume único, destinado ao uso nos três anos finais da Educação Básica. 


\section{ANÁlISE DAS APT NOS LIVROS DIDÁTICOS DE MATEMÁTICA: A INTERTEXTUALIDADE E A INTERDISCURSIVIDADE EM EVIDÊNCIA}

A coleção de Matemática que analisamos apresenta uma perspectiva diferenciada no que se refere às atividades de produção de textos escritos. Em termos quantitativos, encontramos vinte e três APT, a maioria, dez, sem especificação do gênero a ser produzido, e outras variando entre relatórios, cartazes, painéis e até a sugestão de produção de um “livreto com narrativa”.

Podemos afirmar com segurança que os autores da coleção têm consciência da necessidade de instrumentalizar o aluno o mínimo o suficiente para o trabalho da produção textual, incluindo aí a necessidade de especificação do gênero. Há uma relativa diversidade de gêneros discursivos e tipos textuais a serem produzidos. Embora identificamos como SEG, sigla por nós utilizada para identificar os textos sugeridos à produção que não são explicitamente denominados pelos autores, a análise das APT desta coleção, como um tudo, possibilita-nos inferir que a intenção dos autores é que os alunos do EM produzam breves biografias de determinados filósofos ou matemáticos, cujo "enredo" ou tema norteador (ponto de vista) do texto seja o contexto histórico-social e a produção do conhecimento matemático relacionado ao trabalho do filósofo ou matemático em estudo.

Além disso, contamos vinte e três as atividades que se referiam especificamente à produção de textos escritos, mas, ao longo de toda a coleção, outros gêneros discursivos foram mencionados, com os mesmos objetivos e a mesma regularidade enunciativa. Encontramos sugestão de produção e apresentação de debates, exposições, palestras etc., eventos e gêneros que, por serem formais, demandam, necessariamente, o auxílio da escrita. Contudo, apesar dessa "consciência dos gêneros discursivos" por parte dos autores, em nenhuma dessas atividades encontramos definição de quaisquer dos gêneros sugeridos, nem tampouco indicação de como os gêneros se estruturam ou funcionam. Há uma regularidade enunciativa que tende para os registros formais da produção escrita. Podemos também perceber o pressuposto de que os alunos já conhecem o gênero, no sentido de saber produzi-lo com desenvoltura, ou ainda o pressuposto de que não seria obrigação do livro didático fornecer as orientações de como escrevê-los. Os autores se contentam com os comandos "cada grupo deve produzir um relatório", "sugerimos que você e seus colegas de grupo construam um painel cujo tema seja: 'A geometria e a arte"'.

Entretanto, apesar dessa ausência de um trabalho mais significativo em relação aos gêneros discursivos a serem produzidos, a análise das atividades em geral nos permite afirmar que essa coleção de livros didáticos de Matemática traz importantes contribuições para a proficiência de produção de textos escritos pelo aluno do EM, visto que as atividades são bem formuladas, apresentam boa contextualização histórica, o que permite que a produção do aluno acesse os conhecimentos disponíveis na memória científica, isto é, por meio de relações intertextuais e interdiscursivas o aluno encontra apoio nos textos presentes nos livros didáticos e nas fontes de referência citadas, sugeridas nas próprias atividades. Somente isso, contextualização e informatividade (obtida por relações intertextuais e interdiscursivas), não é o suficiente, mas é, sem dúvida, uma boa base para uma produção textual mais rica e, quiçá, mais autêntica. A análise da coleção de Matemática nos permitiu identificar a seguinte situação das APT nela incluídas:

No que se refere ao quesito tipologia textual, há relativa diversidade de gêneros discursivos e de tipos textuais a serem produzidos. Diversidade relativa, repetimos, já que a coleção apresenta como sugestão de produção os gêneros "breve biografia” (SEG), relatórios, cartazes, painéis e livreto narrativo, sem qualquer especificação do tipo textual a ser produzido, a não ser no "livreto”, em que vem especificada a narrativa. Além disso, há ainda a problemática da ambiguidade de os "cartazes" e os "painéis" serem considerados gêneros discursivos ou simples suportes de gêneros. Em nossa classificação, resolvemos por incluí-los na categoria de gêneros, conforme o fez Costa (2009), pelo "teor" da atividade sugerida aos alunos, isto é, pelo trabalho de composição desses gêneros, uma vez que as atividades em que eles aparecem não se diferem das demais, onde são sugeridos outros gêneros discursivos, 
tematicamente bem orientados. Em relação ao item diversidade de variedades e registros adequados à situação de produção, podemos afirmar que os registros subtendidos são adequados e diversos ao contexto formal da escrita, o que não há, necessariamente, é a diversidade de contextos.

Quanto ao quesito condições de produção, encontramos de positivo somente o fato de as atividades serem bem delineadas, no sentido de o aluno do EM poder compreender prontamente o objetivo do texto a ser produzido, que é a contextualização histórica do conhecimento de Matemática a ser estudado na unidade do livro. Há também a proposta de socialização dos textos, pois as atividades devem ser feitas em grupo e há ainda a sugestão de troca de textos entre os grupos. A esse respeito, todavia, faltou às APT orientação para a divulgação dos textos para leitores externos à situação escolar ou, ao menos, externos à sala de aula.

Em relação ao quesito contribuição para a construção da textualidade pelo aluno, percebemos como bastante positivo o item contribuição para a elaboração temática, pois as atividades são ricas em informações, com textos auxiliares e complementares e ainda seções adjacentes às APT com indicações de outras referências bibliográficas, além de indicações de sites da internet onde se podem obter dados adicionais sobre o tema a ser escrito. Além disso, o texto a ser produzido precede o estudo do conteúdo matemático propriamente dito, sendo essa, portanto, uma atividade de contextualização, como já afirmamos. Quanto ainda a esse quesito, falta às APT presentes nesta coleção a contribuição para a elaboração da forma composicional do texto, pois em nenhum momento há referência à estrutura textual ou à forma do gênero. Percebemos também a ausência de contribuição para a elaboração do texto de acordo com as convenções da escrita.

No que diz respeito ao item contribuição para as operações exigidas na produção, encontramos proposta de planejamento, de revisão e de reelaboração dos textos, conforme podem ser percebidas nas APT 04 e 06. Nessas atividades, vemos a síntese desses processos em enunciados como "Amplie seu conhecimento sobre o assunto fazendo uma pesquisa com seus colegas de grupo para obter dados que possibilitem a elaboração de um texto cujo título seja 'Euler e a contextualização histórica”, e "Discuta com os colegas de grupo as estratégias a serem usadas na pesquisa, passando pela coleta de dados, organização, análise e estruturação do texto", e também "Retomem o texto, avaliem as críticas anotadas, discutam se elas contribuem para aperfeiçoá-lo e façam a redação final".

Quanto ao quesito formulação das propostas, já fomos categóricos ao afirmar que as APT são bem estruturadas, com objetivos claros, variedade na formulação (embora mantendo certa regularidade) e, mesmo não havendo progressão nas atividades, o nível de complexidade se adéqua ao conteúdo e ao contexto histórico a ser estudado.

Em relação ao quesito avaliação dos textos produzidos, há em quase todas as APT a preocupação dos autores em os textos serem avaliados por colegas e por professores, com a sugestão de que os alunos devem submeter os textos a críticas e ponderá-las para ver se elas contribuem ou não para a melhoria dos textos. Após esse processo, os autores sugerem, então, a reescrita. Contudo, faltam orientações explícitas de submissão dos textos a leitores externos à situação escolar, em um momento talvez de culminância, exposição do "produto final" das atividades. O Quadro 02, a seguir, representa a síntese dessas conclusões: 


\begin{tabular}{|c|c|c|c|}
\hline $\begin{array}{c}\text { ATIVIDADES DE PRODUÇÃO DE TEXTOS ESCRITOS NOS LIVROS } \\
\text { DIDÁTICOS DE MATEMÁTICA }\end{array}$ & \multicolumn{3}{|c|}{$\begin{array}{c}\text { PRESENÇA / AUSÊNCIA } \\
\text { DAS CARACTERÍSTICAS A SEGUIR E } \\
\text { IDENTIFICAÇÃO DAS APT. }\end{array}$} \\
\hline Tipologia textual & Sim & Não & APT \\
\hline Diversidade de gêneros e tipos textuais & $\mathrm{X}$ & & $4,5,6,7$ \\
\hline Diversidade de variedades e registros adequados à situação de produção & $\mathrm{X}$ & & $4,5,6,7$ \\
\hline \multicolumn{4}{|l|}{ Condições de produção } \\
\hline \multicolumn{4}{|l|}{ Explicitação da situação de produção do texto: } \\
\hline a) indicação de objetivos para a produção & $\mathrm{X}$ & & $4,5,6,7$ \\
\hline b) indicação de destinatários para o texto & & $\mathrm{X}$ & \\
\hline c) indicação do contexto social de circulação do texto & & $\mathrm{X}$ & \\
\hline d) indicação do veículo ou suporte & & $\mathrm{X}$ & \\
\hline e) indicação do gênero textual & $\mathrm{X}$ & $\mathrm{X}$ & $4,5,6,7$ \\
\hline f) indicação da variedade e/ou registro & & $\mathrm{X}$ & \\
\hline Proposta de socialização dos textos produzidos & $\mathrm{X}$ & & $4,5,6,7$ \\
\hline \multicolumn{4}{|l|}{ Contribuição para a construção da textualidade pelo aluno } \\
\hline Contribuição para a elaboração temática & $\mathrm{X}$ & & $4,5,6,7$ \\
\hline Contribuição para construção da forma composicional do texto & & $\mathrm{X}$ & \\
\hline $\begin{array}{l}\text { Contribuição para a elaboração do texto de acordo com as convenções da } \\
\qquad \text { escrita }\end{array}$ & & $\mathrm{X}$ & \\
\hline \multicolumn{4}{|l|}{ Contribuição para as operações exigidas na produção: } \\
\hline a) propostas de planejamento & $\mathrm{X}$ & & $4,5,6,7$ \\
\hline b) proposta de revisão de texto & $\mathrm{X}$ & & $4,5,6,7$ \\
\hline c) proposta de reelaboração de textos & $\mathrm{X}$ & & $4,5,6,7$ \\
\hline \multicolumn{4}{|l|}{ Formulação das propostas } \\
\hline Adequação em relação aos objetivos & $\mathrm{X}$ & & $4,5,6,7$ \\
\hline Variedade na formulação & $\mathrm{X}$ & & $4,5,6,7$ \\
\hline Clareza e correção na formulação & $\mathrm{X}$ & & \\
\hline Progressão nas atividades & & $\mathrm{X}$ & \\
\hline \multicolumn{4}{|l|}{ Avaliação dos textos produzidos } \\
\hline Presença significativa de propostas de autoavaliação & $\mathrm{X}$ & & $4,5,6,7$ \\
\hline Presença de proposta de avaliação coletiva, na sala de aula & $\mathrm{X}$ & & $4,5,6,7$ \\
\hline $\begin{array}{l}\text { Presença de sugestão de leitura / avaliação por leitores externos à situação } \\
\text { escolar }\end{array}$ & & $\mathrm{X}$ & \\
\hline
\end{tabular}




\section{CONSIDERAÇÕES FINAIS}

Que condições de escrita são oferecidas aos alunos do Ensino Médio através das atividades de produção de textos presentes nos livros didáticos fornecidos pelo Programa Nacional do Livro para o Ensino Médio (PNLEM)? Até que ponto as atividades de produção de textos escritos presentes em edições recentes de livros didáticos do Ensino Médio contribuem para a formação de produtores de textos autênticos? Que gêneros discursivos são sugeridos como atividades de produção de textos nos livros didáticos do Ensino Médio? Que concepções e/ou pressupostos teóricos sobre língua e sobre texto podem ser inferidos a partir da análise das atividades de produção de textos presentes em edições recentes dos manuais didáticos do Ensino Médio? A partir desses questionamentos, a realização da pesquisa e a escrita da tese de doutoramento de onde procede este artigo, como uma brevíssima síntese, nos permitiram chegar aos seguintes resultados:

As atividades de produção de textos investigadas não atenderam satisfatoriamente aos critérios da análise que empreendemos, de modo que podemos concluir que as APT presentes nos livros didáticos do Ensino Médio distribuídos pelo PNLEM 2009 e adotados pelas três escolas de nossa convivência não contribuem para o desenvolvimento da proficiência de produção de textos escritos pelos alunos. Faltam às atividades sugestões de trabalho com a diversidade de gêneros discursivos, tipos e registros que se adéquem à situação de produção. Não se respeitam nessas APT as condições de produção dos textos conforme são produzidos e postos em circulação cotidiana e corriqueiramente na vida em sociedade, além dos muros da escola. Não há contribuição para a construção da textualidade do aluno. As propostas de produção de textos não são bem formuladas e na maioria das APT não há sugestão de avaliação dos textos produzidos.

Dos livros didáticos investigados, apenas os de Matemática apresentam atividades de produção de textos que podem contribuir mais significativamente para o desenvolvimento de competências e habilidades de produção de textos escritos, visto que atenderam afirmativamente à maioria dos critérios do quadro de análise.

Retomando Antunes (2009, p. 167, grifos da autora), lembramos que para essa autora "[...] o insucesso da escrita escolar é responsabilidade mais de outros fatores do que do componente linguístico". Em outras palavras, se os alunos deixam de aprender a escrever não é porque lhes falta competência linguística para tal empreendimento, mas porque lhes faltam as orientações adequadas e as condições propícias ao uso da escrita. Falta aos professores e aos autores dos livros didáticos o discernimento de imaginá-los, os alunos, percebê-los, olhá-los e vê-los como autênticos usuários da língua e, como tais, capazes de aprender a escrever com desenvoltura e prenhes de significados. Para tanto, é preciso uma mudança radical (de raiz!) na concepção de língua e de texto, para deixarem emergir plenamente outra ordem de discurso, o do discurso contrário ao autoritarismo que se percebe nas atividades tradicionais de produção de textos das escolas do Ensino Médio.

\section{REFERÊNCIAS}

ABAurre, M. L.; PONTARA, M. N.; FADEL, T. Português: língua, literatura, produção de texto. São Paulo: Moderna, 2005. (Volumes 1, 2, 3: Ensino Médio)

AMARAL, Emília et al. Novas palavras: português, ensino médio. 2. ed. São Paulo: FTD, 2003.

ANTUNES, I. Aula de português: encontro e interação. São Paulo: Parábola, 2003.

ANTUNES, I. Lutar com palavras: coesão e coerência. São Paulo: Parábola, 2005.

ANTUNES, I. Língua, texto e ensino: outra escola possível. São Paulo: Parábola, 2009.

BAKHTIN, M. Estética da criação verbal. São Paulo: Martins Fontes, 2003.

Santos | atividades de produção de textos em livros didáticos do ensino médio: uma prática discursiva 
BAKHTIN, M. [VOLOCHINOV]. Marxismo e filosofia da linguagem. 11. ed. São Paulo: Hucitec, 2004.

BUZEN, C.; ROJO, R. Livro didático de língua portuguesa como gênero do discurso: autoria e estilo. In: COSTA VAL, M. da G.; MARCUSCHI, B. (Org.). Livros didáticos de língua portuguesa: letramento e cidadania. Belo Horizonte: Autêntica, 2005. p. 73-117.

COSTA VAL, M. da G.. Atividades de produção de textos escritos em livros didáticos de $5^{\text {a a }} 8^{\text {a }}$ séries do ensino fundamental. In: ROJO, Roxane. BATISTA, Antônio Augusto (Org.). Livro didático de língua portuguesa, letramento e cultura da escrita. Campinas: Mercado de Letras, 2003. p. 125-152.

COSTA, S. R. Dicionário de gêneros textuais. 2. ed. Belo Horizonte: Autêntica, 2009.

FURLANETTO, Maria Marta. Práticas discursivas: desafio no ensino de língua portuguesa. In: CORREA, D. A.; SALEH, P. B. de O. Práticas de letramento no ensino: leitura, escrita e discurso. São Paulo: Parábola, 2007. p. 131-150.

GERALDI, J. W. Portos de passagem. 4. ed. São Paulo: Martins Fontes, 1997.

MARCUSCHI, L. A. Produção textual, análise de gêneros e compreensão. São Paulo: Parábola, 2008.

ORLANDI, E. P. As formas do silêncio: no movimento dos sentidos. Campinas: Editora da UNICAMP, 1997.

SANTOS, A. P. dos. Sobre o conteúdo de língua portuguesa: discursos em oposição, embate, ambiguidade e entrelaçamento. 2007. 132f. Dissertação (Mestrado em Letras) - Programa de Pós-Graduação em Letras e Linguística, Universidade Federal da Bahia, Salvador, 2007.

SANTOS, A. P. dos. Atividades de produção de textos em livros didáticos do ensino médio: dos gêneros textuais à análise de discurso. 2010. 176f. Tese (Doutorado em Letras) - Programa de Pós-Graduação em Letras e Linguística, Universidade Federal da Bahia, Salvador, 2010 .

SILVA, C. X. da; BARRETO FILHO, B. Matemática aula por aula. 2. ed. São Paulo: FTD, 2005. (Volumes 1, 2, 3: Ensino Médio) 